\title{
Pengaruh Dukungan Keluarga dan Teman Sebaya terhadap Kecemasan Belajar saat Pandemi Covid 19 pada Remaja
}

\author{
Chaerani, Evin Novianti \\ Fakultas Ilmu Kesehatan, Universitas Pembangunan Veteran Jakarta
}

\begin{abstract}
Abstrak
Latar Belakang: Pandemi covid 19 mempengaruhi bidang pendidikan dengan diberlakukannya pembelajaran jarak jauh sehingga dapat menimbulkan dampak psikologis bagi remaja. Dalam pelaksanaannya maka dibutuhkan dukungan keluarga dan teman sebaya agar remaja merasa lebih diperhatikan dan disayangi. Penelitian bertujuan mengetahui hubungan dukungan keluarga dan teman sebaya terhadap kecemasan dalam proses pembelajaran saat pandemi covid 19 pada siswa di SMPN 5 Depok.

Metode: Studi cross sectional dengan teknik simple randoom sampling sebanyak 242 responden. Analisis data menggunakan uji chi square.

Hasil: Studi menemukan pengaruh antara dukungan keluarga dengan kecemasan belajar ( $p$ value=0,002) dan dukungan teman sebaya dengan kecemasan belajar ( $p$ value=0,025) pada siswa di SMPN 5 Depok.

Kesimpulan: Hasil penelitian menunjukan bahwa remaja yang memiliki dukungan keluarga dan teman sebaya yang baik akan memberikan dampak dalam belajar yaitu meminimalisir terjadinya kecemasan belajar, khususnya saat pandemi covid-19. Dukuungan keluarga dan teman sebaya mempunyai peranan penting untuk memotivasi remaja sehingga mengurangi kecemasan.

Kata Kunci : Dukungan keluarga, dukungan teman sebaya, remaja, kecemasan belajar.
\end{abstract}

\section{The Effect of Family and Peer Support on Study Anxiety during The Covid-19 Pandemic in Adolescents}

Abstract

Background: The COVID-19 pandemic has affected the education sector with the implementation of distance learning so that it can have a psychological impact on teenagers. In its implementation, it takes the support of family and peers so that teenagers feel more cared for and loved. This study aims to determine the relationship between family and peer support for anxiety in the learning process during the COVID-19 pandemic in students at SMPN 5 Depok.

Methods: Cross sectional study with simple random sampling technique as many as 242 respondents. Data analysis using chi square test.

Results: The study found the effect of family support with learning anxiety ( $p$ value $=0.002$ ) and peer support with learning anxiety ( $p$ value $=0.025$ ) in students at SMPN 5 Depok.

Conclusion: The results of the study show that teenagers who have good family and peer support will have an impact on learning, namely minimizing the occurrence of online learning anxiety during the covid-19 pandemic. Family and peer support has an important role to motivate adolescents so as to reduce anxiety.

Keywords: Family support, peer support, adolescents, anxiety in learning.

Korespondensi: Chaerani

Email: e_nov78@yahoo.co.id 


\section{PENDAHULUAN}

Masa remaja merupakan proses psikologis dan sosial dari seorang anak hingga menjadi dewasa ${ }^{1}$. Masa remaja dapat dikatakan sebagai periode stres psikologis dan fisiologis yang meningkat karena faktor sosial, kognitif, dan biologis yang terjadi selama masa perkembangan $^{2}$. Jadi masa remaja merupakan peralihan dari masa kanak-kanak menjadi dewasa yang akan akan menimbulkan berbagai perubahan fisik dan psikis.

Sejak COVID 19 diumumkan sebagai pandemi, maka Kemendikbud menyarankan institusi perguruan tinggi untuk melakukan pembelajaran jarak jauh dan menganjurkan para siswa untuk belajar dari rumah. Pembelajaran yang dilakukan selama pandemi COVID-19 yaitu pembelajaran daring. Pembelajaran daring pada seluruh siswa mulai dari sekolah dasar sampai perguruan tinggi dapat mempengaruhi kesehatan mental siswa ${ }^{3}$. Saat anak-anak dan remaja isolasi di rumah selama COVID-19 mengakibatkan kecemasan yang disebabkan oleh sistem pendidikan, aktivitas fisik, dan kurangnya sosialisasi ${ }^{4}$.

Indonesia tercatat memiliki prevalensi gangguan mental emosional pada remaja berusia 15 tahun ke atas sebanyak 9,8\% dari jumlah penduduk Indonesia yang dimana angka tersebut mengalami peningkatan dari tahun 2013 yaitu sebanyak 6\%5. Gangguan mental emosional merupakan gangguan psikologis yang paling sentral pada saat kondisi pandemi covid-19, khususnya pada remaja yang menjalani proses pembelajaran daring.

Kecemasan yang terjadi dalam proses belajar jarak jauh saat pandemi covid-19 dapat disebut dengan kecemasan akademik. Kecemasan akademik adalah kondisi yang disebabkan oleh sistem pendidikan, tekanan akademik, dan tugas yang banyak sehingga akan mempengaruhi siswa dalam proses berpikir, emosi, fisik, dan perilaku' . Dampak kecemasan akademik apabila tidak diatasi dapat mengakibatkan perubahan fisik, emosi, kognitif, dan perilaku pada siswa. Adapun upaya untuk meminimalisir kecemasan pada siswa melalui sumber koping meliputi keluarga dan teman sebaya.

Dukungan emosional yang diberikan keluarga, membuat siswa merasakan kesejahteraan sehingga menimbulkan perasaan senang, nyaman, dan $\operatorname{aman}^{7}$. Dukungan keluarga yang dapat dilakukan orang tua dalam proses pembelajaran di rumah yaitu dengan memberikan pendampingan sebagai motivator belajar, serta memberikan fasilitas pada anak ${ }^{8}$. Sedangkan dukungan teman sebaya merupakan bentuk kasih sayang dari teman sebaya berupa perhatian, bantuan, dan penghargaan sehingga dapat memberi kenyamanan secara fisik maupun psikis yang dapat terjadi karena adanya interaksi ${ }^{9}$. Hal tersebut dapat terjadi karena kesamaan usia dan kebutuhan yang hampir sama sehingga dukungan teman sebaya sangat berarti bagi remaja untuk membuat remaja bereksplorasi lebih terhadap dunia luar dengan cara saling bertukarnya informasi dan interaksi sosial lainnya ${ }^{10}$.

Dari hasil studi pendahuluan yang dilakukan pada 37 remaja di SMPN 5 Depok menunjukkan bahwa sebagian besar remaja merasa cemas yang ditandai dengan pusing, sulit berkonsentrasi, murung, sensitif, sakit perut, sulit untuk tidur, hingga remaja sering menyendiri karena kecemasan yang dialaminya. Gejala tersebut dirasakan sejak dilakukannya pembelajaran online di rumah. Dari gejela yang dirasakan, remaja menjelaskan banyak hambatan yang dirasakan selama belajar online di rumah yang mengakibatkan kecemasan pada remaja meningkat. Oleh karena itu, penelitian ini dilakukan untuk mengetahui lebih lanjut pengaruh adanya dukungan keluarga dan teman sebaya terhadap kecemasan belajar yang dialami remaja khususnya di SMPN 5 Depok.

\section{METODE}

Studi cross sectional dilakukan di SMPN 5 Depok dengan sampel yang berjumlah 242 remaja dengan menggunakan simple random sampling dengan kriteria inklusi yaitu siswa/i kelas VIII dan IX di SMPN 5 Depok dan bersedia menjadi responden. Pengambilan data dilakukan dengan kuesioner melalui google form yang terdiri dari empat bagian yaitu data demografi, kecemasan, dukungan keluarga, dan dukungan teman sebaya. Indikator penilaian pada kecemasan menggunakan kuesioner baku dari Reynolds dan Richmond yaitu Revised Children's Manifest Anxiety Scale (RCMAS) yang berupa gejala fisik, perhatian sosial, dan over sensitif pada remaja. Kuesioner dijawab dengan pilihan "Ya" atau "Tidak" pada 28 pertanyaan sehingga didapatkan total skor untuk mengkategorikan normal yaitu 0-19 atau cemas klinis dengan nilai 20-28, untuk kuesioner dukungan keluarga dilihat dari aspek 
dukungan emosional, instrumental, dan dukungan informasi yang dimodifikasi dari penelitian sebelumnya dengan jawaban menggunakan skala likert (selalu, sering, kadang-kadang, jarang, dan tidak pernah) dan diukur berdasarkan nilai median dengan batasan $\geq 53$ untuk mendapatkan kategori baik, sedangkan $<53$ untuk kategori kurang ${ }^{11}$.

Sedangkan pada kuesioner dukungan teman sebaya dilihat dari dukungan penghargaan, emosional, jejaring sosial, informasi, dan dukungan instrumental yang dimodifikasi dari penelitian sebelumnya dengan jawaban menggunakan skala likert (sangat setuju, setuju, tidak setuju, sangat tidak setuju) dan diukur berdasarkan nilai median dengan batasan $\geq 72$ untuk mendapatkan kategori tinggi, sedangkan $<72$ untuk kategori rendah ${ }^{12}$. Penelitian ini sudah mendapatkan persetujuan etik dari Komite Etik Penelitian Kesehatan UPNVJ dengan nomor 180/IV/2021/KEPK.

Pada kuesioner dukungan keluarga telah dilakukan uji validitas dengan $r$ hitung $>r$ tabel $(0,361)$ didapatkan hasil bahwa 19 dari 21 pertanyaan dinyatakan valid dengan uji reliabilitas sebesar 0,941 yang berarti kuesioner sangat reliabel. Sedangkan pada kuesioner dukungan teman sebaya uji validitas dengan $\mathrm{r}$ hitung $>\mathrm{r}$ tabel $(0,361)$ diperoleh hasil bahwa 24 dari 30 pertanyaan dinyatakan valid dengan uji reliabilitas sebesar 0,903 sehingga dinyatakan kuesioner dukungan teman sebaya sangan reliabel. Analisis data dalam penelitian ini menggunakan uji chi square.

\section{HASIL}

Berikut adalah hasil penelitian pada variabel univariat dan bivariat yang dilakukan pada remaja di SMPN 5 Depok.

Tabel 1 Distribusi Usia $(n=242)$

\begin{tabular}{lccccc}
\hline Variabel & M & Me & SD & $\begin{array}{c}\text { Min- } \\
\text { Max }\end{array}$ & $\begin{array}{c}\mathbf{9 5 \%} \\
\mathbf{C I}\end{array}$ \\
\hline Usia & \multirow{2}{*}{14,35} & 14,00 & 0,666 & $\begin{array}{c}13 \\
-\end{array}$ & $\begin{array}{c}14,27 \\
- \\
\end{array}$ \\
& & & & 16 & 14,43 \\
\hline
\end{tabular}

Tabel 2 Distribusi Jenis Kelamin, Dukungan Keluarga, dan Teman Sebaya $(n=242)$

\begin{tabular}{lcc}
\hline \multicolumn{1}{c}{ Variabel } & F & \% \\
\hline Jenis Kelamin & & \\
Laki- laki & 80 & 33,1 \\
Perempuan & 162 & 66,9 \\
\hline Dukungan Keluarga & & \\
Baik & 123 & 50,8 \\
Kurang & 119 & 49,2 \\
\hline Dukungan Teman Sebaya & & \\
Tinggi & 126 & 52,1 \\
Rendah & 116 & 47,9 \\
\hline Kecemasan & & \\
Normal & 205 & 84,7 \\
Cemas klinis & 37 & 15,3 \\
\hline
\end{tabular}

Berdasarkan tabel 2 diketahui sebanyak 80 orang $(33,1 \%)$ adalah laki-laki dan sisanya 162 orang $(66,9 \%)$ adalah perempuan. Pada dukungan keluarga menunjukan hasil bahwa mayoritas remaja memiliki dukungan keluarga yang baik dengan jumlah sebanyak $123(50,8 \%)$ sedangkan siswa dengan dukungan keluarga yang kurang baik sebanyak 119 orang $(49,2 \%)$. Sedangkan siswa dengan dukungan teman sebaya yang tinggi sebanyak 126 orang $(52,1 \%)$ dan siswa dengan dukungan teman sebaya yang rendah sebanyak 116 orang $(47,9 \%)$. Pada variabel kecemasan didapatkan bahwa mayoritas siswa dengan kecemasan normal sebanyak 205 orang $(84,7 \%)$ sedangkan siswa dengan kecemasan klinis sebanyak 37 orang $(15,3 \%)$.

Tabel 3 Hubungan Dukungan Keluarga dengan Kecemasan pada Remaja $(n=242)$

\begin{tabular}{|c|c|c|c|}
\hline \multirow{2}{*}{ Variabel } & \multicolumn{2}{|c|}{ Kecemasan } & \multirow{2}{*}{$\begin{array}{c}\mathbf{P} \\
\text { Value }\end{array}$} \\
\hline & Klinis & Normal & \\
\hline \multicolumn{4}{|c|}{ Dukungan Keluarga } \\
\hline Kurang & $\begin{array}{c}27 \\
(22,7 \%)\end{array}$ & $\begin{array}{c}92 \\
(77,3 \%)\end{array}$ & \multirow{3}{*}{$\mathbf{0 , 0 0 2}$} \\
\hline Baik & $\begin{array}{c}10 \\
(8,1 \%)\end{array}$ & $\begin{array}{c}113 \\
(91,9 \%)\end{array}$ & \\
\hline Total & $\begin{array}{c}37 \\
(15,3 \%)\end{array}$ & $\begin{array}{c}205 \\
(84,7 \%)\end{array}$ & \\
\hline $\begin{array}{l}\text { Dukungan } \\
\text { Teman } \\
\text { Sebaya }\end{array}$ & & & \multirow{4}{*}{$\mathbf{0 , 0 2 5}$} \\
\hline Rendah & $\begin{array}{c}24 \\
(20,7 \%)\end{array}$ & $\begin{array}{c}92 \\
(79,3 \%)\end{array}$ & \\
\hline Tinggi & $\begin{array}{c}13 \\
(10,3 \%)\end{array}$ & $\begin{array}{c}113 \\
(89,7 \%)\end{array}$ & \\
\hline Total & $\begin{array}{c}37 \\
(15,3 \%)\end{array}$ & $\begin{array}{c}205 \\
(84,7 \%)\end{array}$ & \\
\hline
\end{tabular}


Berdasarkan tabel 3 diketahui siswa yang mendapatkan dukungan keluarga yang kurang mengalami cemas klinis sebanyak 27 siswa $(22,7 \%)$ sedangkan siswa yang mendapatkan dukungan keluarga yang baik mengalami cemas klinis sebanyak 10 siswa $(8,1 \%)$. Siswa yang mendapatkan dukungan keluarga yang kurang mengalami kecemasan normal sebanyak 92 orang $(77,3 \%)$ sedangkan siswa yang mendapatkan dukungan keluarga yang baik memiliki kecemasan normal sebanyak 113 orang $(91,9 \%)$. Hasil didapatkan nilai $p$-value sebesar 0,002 sehingga terdapat hubungan dukungan keluarga dengan kecemasan pada remaja di SMPN 5 Depok.

Pada siswa dengan dukungan teman sebaya yang rendah mengalami cemas klinis sebanyak 24 siswa $(20,7 \%)$ sedangkan siswa yang mendapatkan dukungan teman sebaya yang tinggi mengalami cemas klinis sebanyak 13 siswa $(10,3 \%)$. Siswa yang mendapatkan dukungan teman sebaya yang tinggi mengalami kecemasan normal sebanyak 113 siswa $(89,7 \%)$ sedangkan siswa dengan dukungan teman sebaya yang rendah memiliki kecemasan normal sebanyak 92 siswa (79,3\%). Hasil analisa chi-square didapatkan nilai $p$ value sebesar 0,025 yang artinya ada hubungan dukungan teman sebaya dengan kecemasan remaja di SMPN 5 Depok.

\section{PEMBAHASAN}

Dukungan keluarga didapatkan hasil mayoritas siswa memiliki dukungan keluarga yang baik. Hasil penelitian menyatakan bahwa pada anak usia remaja yang memiliki dukungan keluarga di Kabupaten Tabanan mayoritas memiliki dukungan keluarga yang tinggi sebanyak 107 orang $(79,9 \%)$ sedangkan remaja yang memiliki dukungan keluarga rendah sebanyak 17 orang $(12,6 \%)^{13}$.

Pada hasil penelitian siswa mayoritas memiliki dukungan teman sebaya yang tinggi. Hasil penelitian menyatakan bahwa dukungan sosial terhadap kecemasan akademik menunjukan hasil mayoritas siswa memiliki dukungan sosial yang sangat tinggi sebanyak 40 siswa $(47,62 \%)$ sedangkan yang memiliki dukungan sosial rendah sebanyak 6 orang $(7,14 \%)^{(14)}$.

\footnotetext{
Dalam hasil penelitian diketahui bahwa didominasi siswa mengalami kecemasan normal. Hasil penelitian ini tidak sejalan oleh penelitian lain yang menyatakan bahwa sebanyak 10,3\% remaja pada sekolah
}

menengah pertama mengalami kecemasan sedang saat kondisi pandemi covid 19, sedangkan pada remaja yang mengalami kecemasan berat hingga sangat berat sebanyak $10 \%{ }^{15}$. Dari hasil penelitian mengenai gambaran kecemasan didapatkan lebih banyak siswa yang mengalami kecemasan normal daripada kecemasan klinis. Hal ini sejalan dengan penelitian yang menyatakan bahwa faktor yang dapat memengaruhi kecemasan belajar pada siswa yaitu seperti motivasi siswa dalam belajar, efikasi diri pada siswa, kebiasaan belajar, dan kesiapan mental maupun fisik pada siswa pada saat pembelajaran ${ }^{16}$. Adapun faktor lain menurut penelitian menyatakan bahwa berbagai pikiran yang ada dalam diri sendiri dapat memengaruhi kecemasan pada individu ${ }^{17}$.

Hasil penelitian didapatkan ada hubungan dukungan keluarga dengan kecemasan belajar pada remaja di SMPN 5 Depok. Remaja dengan dukungan keluarga baik mayoritas mengalami kecemasan normal daripada dukungan keluarga yang kurang. Menurut penelitian lain menyatakan bahwa dalam penelitian terhadap 7.143 siswa di China yang diukur dengan GAD-7 memiliki hasil sebanyak $75,1 \%$ siswa tidak mengalami kecemasan, sebanyak $21,3 \%$ siswa mengalami kecemasan ringan, lalu 2,7\% siswa mengalami kecemasan sedang, sedangkan siswa yang mengalami kecemasan berat sebanyak $0,9 \%$. Kemudian sebanyak $95,04 \%$ siswa mendapatkan dukungan keluarga yang baik sehingga analisis yang didapatkan dalam penelitian ini yaitu $\mathrm{p}$ value $=0,017 \quad(<0,05)$ yang artinya bahwa terdapat hubungan yang signifikan antara dukungan keluarga dengan kecemasan pada remaja ${ }^{18}$. Penelitian tersebut juga melaporkan bahwa dukungan sosial keluarga yang rendah memiliki resiko yang tinggi dalam mengalami tekanan psikologis, sedangkan dukungan sosial keluarga yang tinggi memiliki efek positif pada kecemasan selama epidemi covid 19. Hal ini juga sejalan dengan penelitian yang menyatakan bahwa dukungan sosial dari keluarga, teman, dan masyarakat penting untuk menjaga kesejahteraan dan kesehatan psikologis individu selama epidemi covid $19^{19}$.

Dalam penelitian didapatkan ada hubungan dukungan teman sebaya dengan kecemasan belajar pada remaja di SMPN 5 Depok. Penelitian ini sejalan oleh penelitian yang menyatakan bahwa telah dilakukan survei 
pada 255 siswa di China dengan mengisi kuesioner online terkait dukungan teman sebaya dengan gangguan emosional kecemasan dan depresi yang menyatakan bahwa hasil dukungan sosial teman sebaya dengan kecemasan sebesar $(r=-0,32$ dan $\mathrm{p}<0,01$ ) sehingga siswa yang mendapatkan dukungan teman sebaya lebih besar memiliki gejala kecemasan yang lebih sedikit ${ }^{20}$. Dalam studi ini diketahui bahwa siswa yang mendapatkan dukungan teman sebaya yang tinggi masih memiliki kecemasan sebanyak $10,3 \%$ yang artinya ada faktor lain pemicu terjadinya kecemasan belajar pada siswa. Selama pandemi covid 19 menyebabkan siswa lebih banyak berinteraksi melalui media sosial sehingga hal ini menyebabkan adanya kekeliruan maupun kesalahpahaman dalam komunikasi yang akan berdampak pada kecemasan. Hal ini sejalan dengan penelitian yang menyatakan bahwa rata-rata remaja menggunakan media sosial antara 7-16 jam per hari dengan mayoritas digunakan untuk chatting ${ }^{21}$. Dalam penelitian kualitatif ini salah satu remaja merasa terganggu dalam berinteraksi dengan teman sebaya melalui sosial media sehingga akan menimbulkan masalah baru yang berujung pada kecemasan. Adapun dalam penelitian yang menyatakan bahwa kelebihan informasi dari media sosial akan menyebabkan social media fatique sehingga dapat berdampak pada tekanan kognitif siswa 22. Dampak pada belajar dari social media fatique yaitu persepsi siswa bahwa dalam kegiatan sehari-harinya telah terganggu oleh media sosial yang kaitannya dengan tugas belajar, sehingga kecemasan belajar dapat muncul karena siswa menggunakan media sosial yang berlebihan dari biasanya ${ }^{23}$. Berdasarkan pembahasan faktor tersebut maka dapat menjadikan siswa masih mengalami kecemasan meskipun mendapatkan dukungan teman sebaya yang tinggi. Hal ini menunjukan bahwa kecemasan belajar dan dukungan teman sebaya juga dipengaruhi oleh faktor paparan media sosial.

Namun pada data hasil penelitian juga menunjukan bahwa siswa yang mendapatkan dukungan teman sebaya yang rendah memiliki kecemasan normal yang lebih banyak daripada yang memiliki kecemasan klinis. Faktor lain yang sesuai dengan penelitian yang mengatakan bahwa dengan adanya kemandirian dalam belajar dapat membuat siswa menetapkan keputusan dan menyelesaikan masalahnya sendiri tanpa bergantung pada temannya, sehingga proses pembelajaran siswa berjalan dengan baik yang akan berdampak dengan menurunnya kecemasan dalam proses pembelajaran pada siswa ${ }^{24}$. Berdasarkan pembahasan diatas maka dapat diketahui bahwa dukungan teman sebaya yang rendah belum tentu menyebabkan kecemasan klinis pada siswa dikarenakan oleh faktor kepribadian yang siswa miliki dalam proses pembelajaran saat pandemi covid 19 .

\section{KESIMPULAN}

Dapat disimpulkan dari hasil penelitian ini didapatkan bahwa terdapat mayoritas remaja di SMP Negeri 5 Depok memiliki dukungan keluarga yang baik, memiliki dukungan teman sebaya yang tinggi, serta sebagian besar siswa memiliki kecemasan yang normal dalam proses pembelajaran selama pandemi covid 19. Adapun dalam studi ini diketahui dengan adanya hubungan antara dukungan keluarga dan teman sebaya terhadap kecemasan siswa SMPN 5 Depok dalam proses belajar selama pandemi covid 19 .

\section{SARAN}

Saran diberikan kepada siswa untuk mengetahui pentingnya sumber koping dukungan keluarga dan teman sebaya sehingga dapat termotivasi untuk meningkatkan hubungan dengan keluarga dan teman sebaya sehingga dapat mengontrol kecemasan dalam proses pembelajaran saat pandemi covid 19 . Untuk masyarakat diharapkan memahami pentingnya dukungan keluarga dan teman sebaya sehingga dapat meningkatkan kepekaan dan dukungannya terhadap anak atau remaja disekitar mereka dalam meminimalisir kecemasan. Untuk orang tua dapat memahami pentingnya memberikan dukungan terhadap anaknya seperti melakukan pendampingan, mengawasi, memberikan fasilitas, memberikan motivasi, dan menjadi pendengar yang baik terhadap anaknya dalam proses pembelajaran daring. Diharapkan dapat menjadi dasar bagi institusi pendidikan untuk mengembangkan kemampuan dalam memberikan asuhan keperawatan pada remaja yang menghadapi kecemasan dalam proses pembelajaran dengan meningkatkan hubungan dukungan keluarga dan teman sebaya khususnya dalam kondisi pandemi covid 19. Untuk guru BK atau wali kelas sebagai wadah terhadap siswa dalam berkonsultasi dan berdiskusi terkait 
permasalahan yang dialami siswa selama pembelajaran daring. Untuk penelitian selanjutnya yang akan membahas topik yang serupa agar dijadikan acuan dalam melakukan penelitian selanjutnya dengan lebih menggali faktor yang mempengaruhi kecemasan pada remaja khususnya saat kondisi pandemi covid 19 sehingga dapat menjadi bahasan yang lebih luas.

\section{DAFTAR PUSTAKA}

1. Christian P, Smith ER. Adolescent Undernutrition: Global Burden, Physiology, and Nutritional Risks. Ann Nutr Metab. 2018;72(4):316-28.

2. Katz DA, Peckins MK, Lyon CC. Adolescent stress reactivity: Examining physiological, psychological and peer relationship measures with a group stress protocol in a school setting. J Adolesc. 2019 Jul;74:45-62.

3. Pragholapati A. Covid-19 Impact on Students. 2020;1-6.

4. Jiao WY, Wang LN, Liu J, Fang SF, Jiao FY, Pettoello-Mantovani M, et al. Behavioral and Emotional Disorders in Children during the COVID-19 Epidemic. J Pediatr [Internet]. 2020;221:264-266.e1. Available from: https://doi.org/10.1016/j.jpeds.2020.03. 013

5. Riskesdas. Hasil Utama Riset Kesehatan Dasar [Internet]. 2018 [cited 2021 Feb 4]. Available from: https://kesmas.kemkes.go.id/assets/uplo ad/dir 519d41d8cd98f00/files/Hasilriskesdas-2018_1274.pdf

6. Della Tri Damayamti; Alviyatun Masitoh. Strategi Koping Siswa Dalam Menghadapi Stres Akademik Di Era Pandemi Covid-19. J Multidiscip Stud [Internet]. 2020;4(December):185-98. Available from: http://ejournal.iainsurakarta.ac.id/index. php/academica/article/view/3167

7. Mariatun M, Munir A, Metia C. Hubungan Self Efficacy dan Dukungan Keluarga dengan Kecemasan Siswa pada Pelajaran Matematika Sekolah Menegah Atas Negeri 2 Sinabang. Tabularasa J Ilm Magister Psikol. 2020;2(1):1-7.

8. Lilawati A. Peran Orang Tua dalam Mendukung Kegiatan Pembelajaran di Rumah pada Masa Pandemi. J Obs J
Pendidik Anak Usia Dini. 2020;5(1):549.

9. Halim F. Pengaruh Dukungan Sosial Teman Sebaya dan Kepercayaan Diri Terhadap Kecemasan Belajar Mahasiswa pendidikan Dasar. PiJIES Pendagogik J Islam Elem Sch. 2019;2(2):129-46.

10. Diananda A. Psikologi Remaja Dan Permasalahannya. J ISTIGHNA [Internet]. 2019;4(1):116-33. Available from: http://e-journal.stit-islamicvillage.ac.id/index.php/istighna

11. Nursalam. Metodologi Penelitian Ilmu Keperawatan. 4th ed. Jakarta: Salemba Medika; 2016.

12. Widowati FS. Hubungan Dukungan Sosial Teman Sebaya dengan Penerimaan Diri Remaja Panti Asuhan. Universitas Muhammadiyah Malang; 2018.

13. Apriani DGY, Sudiarsani A. Hubungan Dukungan Orang Tua Terhadap Tingkat Kecemasan Anak Usia Remaja (12-18 th) Pada Saat Pemasangan Infus Di Ruang IRD BRSUD Kabupaten Tabanan. J Med Usada. 2020;3:32-40.

14. Madoni ER, Mardliyah A. Determinasi religiusitas, kecerdasan emosional, dan dukungan sosial terhadap kecemasan akademik siswa. J ConsulenzaJurnal Bimbing Konseling dan Psikol [Internet]. 2021;4(1):1-10. Available from:

http://ejurnal.uij.ac.id/index.php/CONS

15. Zhang C, Ye M, Fu Y, Yang M, Luo F, Yuan J, et al. The Psychological Impact of the COVID-19 Pandemic on Teenagers in China. J Adolesc Heal [Internet]. 2020;67(6):747-55. Available from: https://doi.org/10.1016/j.jadohealth.202 0.08 .026

16. Mukholil. Kecemasan dalam Proses Belajar. J eksponen. 2018;8(1).

17. Musradinur. Stres dan Cara Mengatasinya dalam Perspektif Psikologi. J EDUKASI J Bimbing Konseling. 2016;2(2):183.

18. Cao W, Fang Z, Hou G, Han M, Xu X, Dong J, et al. The psychological impact of the COVID-19 epidemic on college students in China. Psychiatry Res [Internet]. 2020;287(March):112934. Available from: 
https://doi.org/10.1016/j.psychres.2020. 112934

19. Shigemura J, Ursano RJ, Morganstein JC, Kurosawa M, Benedek DM. Public responses to the novel 2019 coronavirus (2019-nCoV) in Japan: Mental health consequences and target populations. Psychiatry Clin Neurosci. 2020;74(4):281-2.

20. Sun Y, Lin SY, Chung KKH. University students' perceived peer support and experienced depressive symptoms during the COVID-19 pandemic: The mediating role of emotional well-being. Int J Environ Res Public Health. 2020;17(24):1-13.

21. Elfiyani NK, Pratomo H, Putri SW, Wahyuni RD, Mukti GA. Gambaran Emosional pada Remaja yang Menjalani Social Distancing selama
Pandemi Covid 19. Qual J Kesehat. 2021;15(1):37-43.

22. Zhang S, Zhao L, Lu Y, Yang J. Do you get tired of socializing? An empirical explanation of discontinuous usage behaviour in social network services. Inf Manag [Internet]. 2016;53(7):904-14. Available from: http://dx.doi.org/10.1016/j.im.2016.03. 006

23. Rahardjo W, Qomariyah N, Mulyani I, Andriani I. Social Media Fatigue pada Mahasiswa di Masa Pandemi COVID19. Psikol Sos. 2020;18(59):12.

24. Nazariah, Andrian R. Pendekatan Kemandirian Belajar terhadap Kecemasan pada Proses Pembelajaran. J Ilm Pendidik dan Pembelajaran. 2018;5(2):52-67. 